\title{
Reference markers of bone turnover for prediction of fracture: a meta-analysis
}

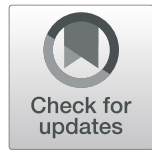

Aixian $\operatorname{Tian}^{1 \dagger}$, Jianxiong $\mathrm{Ma}^{1+}$, Kaiqiang Feng ${ }^{2 \dagger}$, Zhaojie $\mathrm{Liu}^{1 \dagger}$, Lei Chen ${ }^{3+}$, Haobo $\mathrm{Jia}^{4+}$ and Xinlong $\mathrm{Ma}^{1 *}$

\begin{abstract}
Objective: To explore whether bone turnover biomarkers (BTMs), i.e., C-terminal telopeptide of type I collagen (CTX) and procollagen type I aminoterminal propeptide (PINP), are associated with fracture.

Methods: We searched electronic database including PubMed, Embase and Cochrane Library, and the reference lists of relevant articles published from inception to August 22, 2018. An updated meta-analysis was performed to assess the prediction value of CTX and PINP in fracture.

Results: Nine articles met our inclusion criteria and were included in the meta-analysis. The crude and adjusted effect size between PINP and fracture were extracted from two and five studies, respectively. PINP was not associated with fracture incidence without adjusting covariates (crude $\mathrm{GR}, 1.03 ; 95 \% \mathrm{Cl}, 0.91-1.17$ ). After adjusting for potential confounders, PINP demonstrated a significant positive association with fracture (adjusted GR, 1.28; 95\% $\mathrm{Cl}, 1.15-1.42)$. In the subgroup analysis of studies after adjusting covariates, there were significant associations in women. Both the crude $(1.16,95 \% \mathrm{Cl}, 1.04-1.20)$ and adjusted $\mathrm{GR}(1.20,95 \% \mathrm{Cl}, 1.05-1.37)$ shown positive relationships between CTX and fracture, which were extracted from four and six studies, separately. The sensitivity analysis confirmed the stability of the results. In the subgroup analysis of studies after adjusting covariates, there were significant associations in the subgroups of elderly, female, and hip fracture patients.

Conclusions: Our results indicate a statistically significant but modest association between BTMs (s-PINP or s-CTX) and future fracture risk after adjusting for BMD and clinical risk factors. The causal relationship between the two clinical conditions requires future validation with more standardized studies.
\end{abstract}

Registration number: CRD42018107879

Keywords: BTMs, PINP, CTX, Fracture

\section{Background}

Fracture is a worldwide public health problem because of the increased morbidity, mortality, and financial costs [1]. However, the ability to predict and prevent fractures is limited. The current approaches for predicting who might fracture are largely based on the measurement of bone mineral density (BMD) and the inclusion in risk calculators of certain clinical risk factors. Such risk calculators include FRAX, QFRACTURE, and the Garvan calculator [2]. However, BMD indicated osteoporosis only in $30-50 \%$ of patients with major fragility fracture

\footnotetext{
* Correspondence: tjtianaixian@163.com

${ }^{\dagger}$ Aixian Tian, Jianxiong Ma, Kaiqiang Feng, Zhaojie Liu,Lei Chen and Haobo

Jia contributed to this work equally and should be considered co-first authors.

${ }^{1}$ Tianjin Hospital, Tianjin University, Tianjin 300211, China

Full list of author information is available at the end of the article
}

[3]. And the prognostic value of clinical risk factors alone in FRAX is comparable to that of BMD alone [4]. There is an imperious need of identifying additional fracture risk factors not included in currently available strategies.

Bone turnover biomarkers (BTMs) reflect bone formation and resorption and therefore inform the status of bone remodeling. Attractive features of these markers are that samples of blood are easily collected, a variety of assays is available, and sample collection is relatively noninvasive. The development of markers of BTMs has provided an important tool in the clinical and preclinical assessment of bone active interventions. A working group of the International Osteoporosis Foundation (IOF)/International Federation of Clinical Chemistry (IFCC) and Laboratory Medicine Bone Markers Working Group identified one

(C) The Author(s). 2019 Open Access This article is distributed under the terms of the Creative Commons Attribution 4.0 International License (http://creativecommons.org/licenses/by/4.0/), which permits unrestricted use, distribution, and 
bone resorption marker, C-terminal telopeptide of type I collagen (CTX), and one bone formation marker, procollagen type I aminoterminal propeptide (PINP), as the most promising bone turnover markers [5]. Serum PINP (s-PINP) is generated during the synthesis of type I collagen, and serum CTX (s-CTX) is a product of the breakdown of type I collagen containing pyridinium crosslinks.

Recently, there are numerous of studies tried to examine bone turnover marker levels in relation to fragility or osteoporotic fractures. Of those studies, some studies found a positive relationship between bone turnovers and the incidence of fracture $[6,7]$. However, some recent researches represented different results [8-10]. A meta-analysis published in 2014 has been conducted for serum CTX-1 and PINP in ten prospective cohort studies of untreated participants [11]. And it turned out that for 1 standard deviation (SD) increase, the risk of all fractures was 1.18 with CTX and 1.23 with PINP. However, these results were not adjusted for BMD and/or other potential confounders. And the performance characteristics of clinical risk factors (CRFs) and BMD were proved to be strongly associated with the prediction value of fracture risk. For example, in a large meta-analysis, CRFs alone predicted hip fracture with a GR (the gradient of risk) of 2.1/SD and the use of BMD alone provided a higher GR (3.7/SD), and this was improved further with the combined use of CRFs and BMD (4.2/SD) [12].

To our knowledge, data should also be adjusted for bone mineral density and clinical risk factors so that the BTM are evaluated for their value in fracture risk prediction algorithms. Therefore, based on existing evidence, a study needs to be updated and critically evaluates the

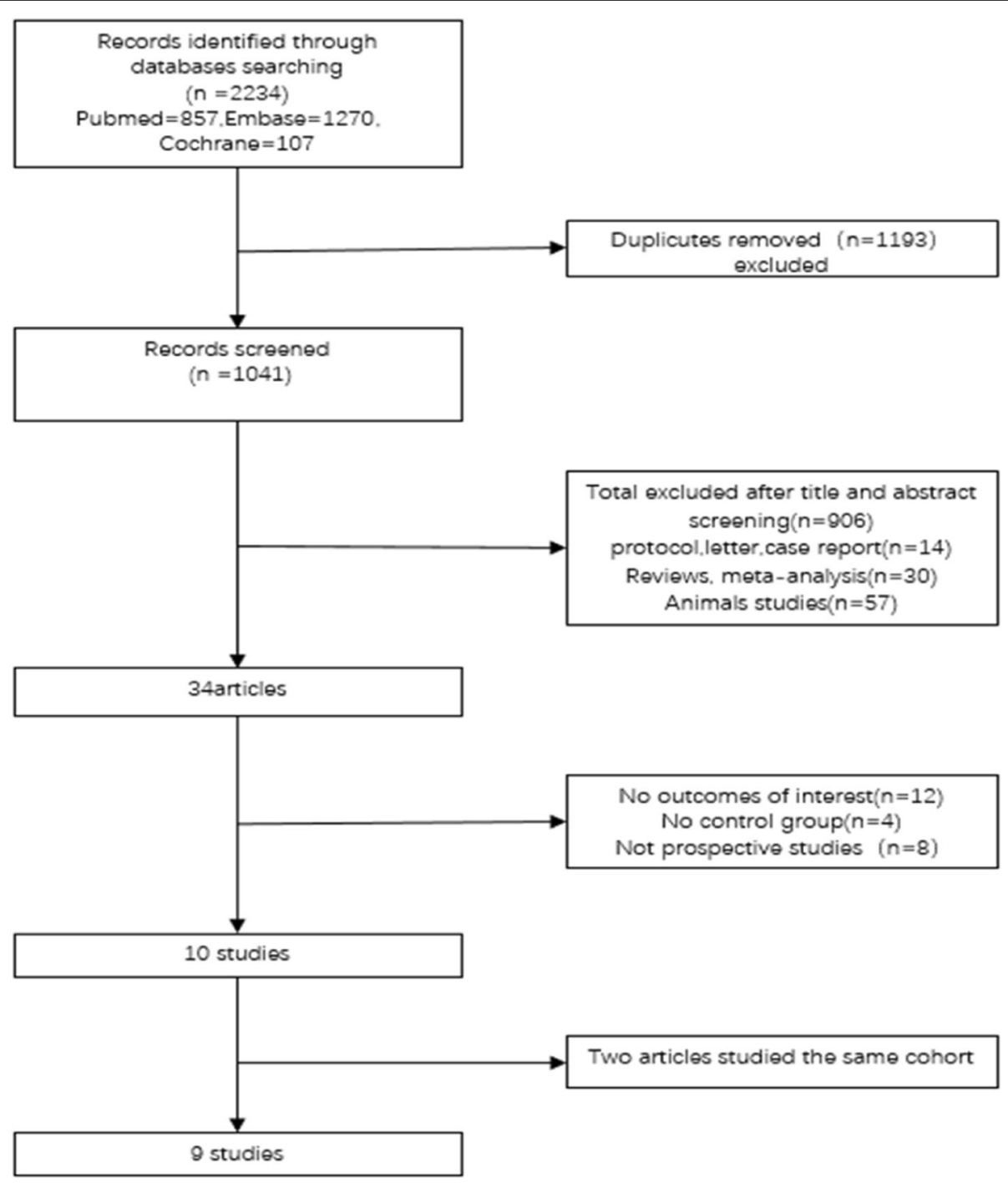

Fig. 1 PRISMA flow diagram for the study selection process 
Table 1 Characteristics of the included studies

\begin{tabular}{llllllll}
\hline Study & BTM & Follow-up (years) & Sex & Age (years) & $\begin{array}{l}\text { Number of } \\
\text { participants }\end{array}$ & Population/setting & Fasting \\
\hline Chapurlat [7] & s-CTX & 3.3 & F & $>75$ & 854 & Population-based registers \\
Garnero [14] & s-CTX & 5 & F & $50-89$ & 435 & Healthy untreated postmenopausal & Yes \\
Gerdhem [17] & s-CTX & 6.5 & F & 75 & 1040 & Population-based nursing home & No \\
Meier [19] & s-PINP,s-CTX & 6.3 & M & $>70$ & 151 & All in city & No \\
Dobnig [20] & s-CTX & 2 & F & $>70$ & 1664 & Nursing home \\
Bauer [21] & s-PINP,s-CTX & 4.6 & M & $>65$ & 5995 & Advert and mass mailing \\
Shigdel [10] & s-PINP,s-CTX & 6.6 & F & $>50$ & 433 & Population-based registers \\
Dai [6] & s-PINP,s-CTX & 5 & F and M & $45-74$ & 200 & Population-based cohort \\
Crandall [8] & s-PINP,s-CTX & 7.13 & F & $50-79$ & 800 & Clinical centers & Yes
\end{tabular}

current evidence-based information about the prediction of fracture by BTMs. In our study, a comprehensive meta-analysis was conducted to assess the potential value of serum PINP or CTX in fracture risk prediction.

\section{Methods}

\section{Searches}

Two reviewers independently searched electronic database including PubMed, Embase, and Cochrane Library based on logic combination of keywords and text words from inception to August 22, 2018, and updated them on October 14, 2018. Search terms included "procollagen Type I N-terminal peptide", " PINP”, "collagen type I trimeric cross-linked peptide", " CTX", and "fractures". Search terms were combined using the Boolean operators "AND" or "OR". The search was restricted to studies of human participants, but we set no search restrictions on follow-up time, patients' age, study size, and the language of articles. Reference lists of relevant articles were manually searched to identify additional trials.

\section{Study inclusion and exclusion criteria}

Studies eligible for inclusion were prospective cohort studies of s-PINP or s-CTX measured at baseline in untreated individuals. Nested case-control and case-cohort studies were also allowed. The primary outcome was the first incident fracture in middle-aged or older men and women. We excluded cross-sectional studies and articles that test OINP or CTX in the urine. Basic science studies, reviews, editorials, letters, case reports, and studies without comparison groups were also excluded.

\section{Data extraction}

Two members of the study team independently assessed all titles and abstracts of identified reports for eligibility.

Table 2 Quality assessment by using the Newcastle-Ottawa Scale for the included studies

\begin{tabular}{|c|c|c|c|c|c|c|c|c|c|}
\hline & $\begin{array}{l}\text { Chapurlat } \\
{[7]}\end{array}$ & $\begin{array}{l}\text { Garnero } \\
{[14]}\end{array}$ & $\begin{array}{l}\text { Gerdhem } \\
{[17]}\end{array}$ & $\begin{array}{l}\text { Meier } \\
{[19]}\end{array}$ & $\begin{array}{l}\text { Dobnig } \\
{[20]}\end{array}$ & $\begin{array}{l}\text { Bauer } \\
{[21]}\end{array}$ & $\begin{array}{l}\text { Shigdel } \\
{[10]}\end{array}$ & $\begin{array}{l}\text { Dai } \\
{[6]}\end{array}$ & $\begin{array}{l}\text { Crandall } \\
{[8]}\end{array}$ \\
\hline \multicolumn{10}{|l|}{ Cohort study } \\
\hline Representativeness of the exposed cohort & + & - & + & + & - & + & + & + & + \\
\hline Selection of the unexposed cohort & + & - & + & + & + & + & + & + & + \\
\hline Ascertainment of exposure & + & + & + & + & + & + & + & + & + \\
\hline $\begin{array}{l}\text { Outcome of interest not present } \\
\text { at the start of the study }\end{array}$ & - & - & - & - & - & - & - & - & - \\
\hline \multicolumn{10}{|l|}{ Control for important factor or additional factor } \\
\hline Study controls for age/sex & + & - & + & + & + & - & + & + & + \\
\hline $\begin{array}{l}\text { Study controls for any other confounding } \\
\text { factors }\end{array}$ & - & - & + & - & + & - & + & + & - \\
\hline Outcome assessment & + & + & + & + & + & + & + & + & + \\
\hline Follow-up long enough for outcomes to occur & + & + & + & + & - & + & + & + & + \\
\hline Adequacy of follow-up of cohorts & + & + & + & + & + & + & + & + & + \\
\hline Total quality scores & 7 & 4 & 8 & 7 & 6 & 6 & 8 & 8 & 7 \\
\hline
\end{tabular}



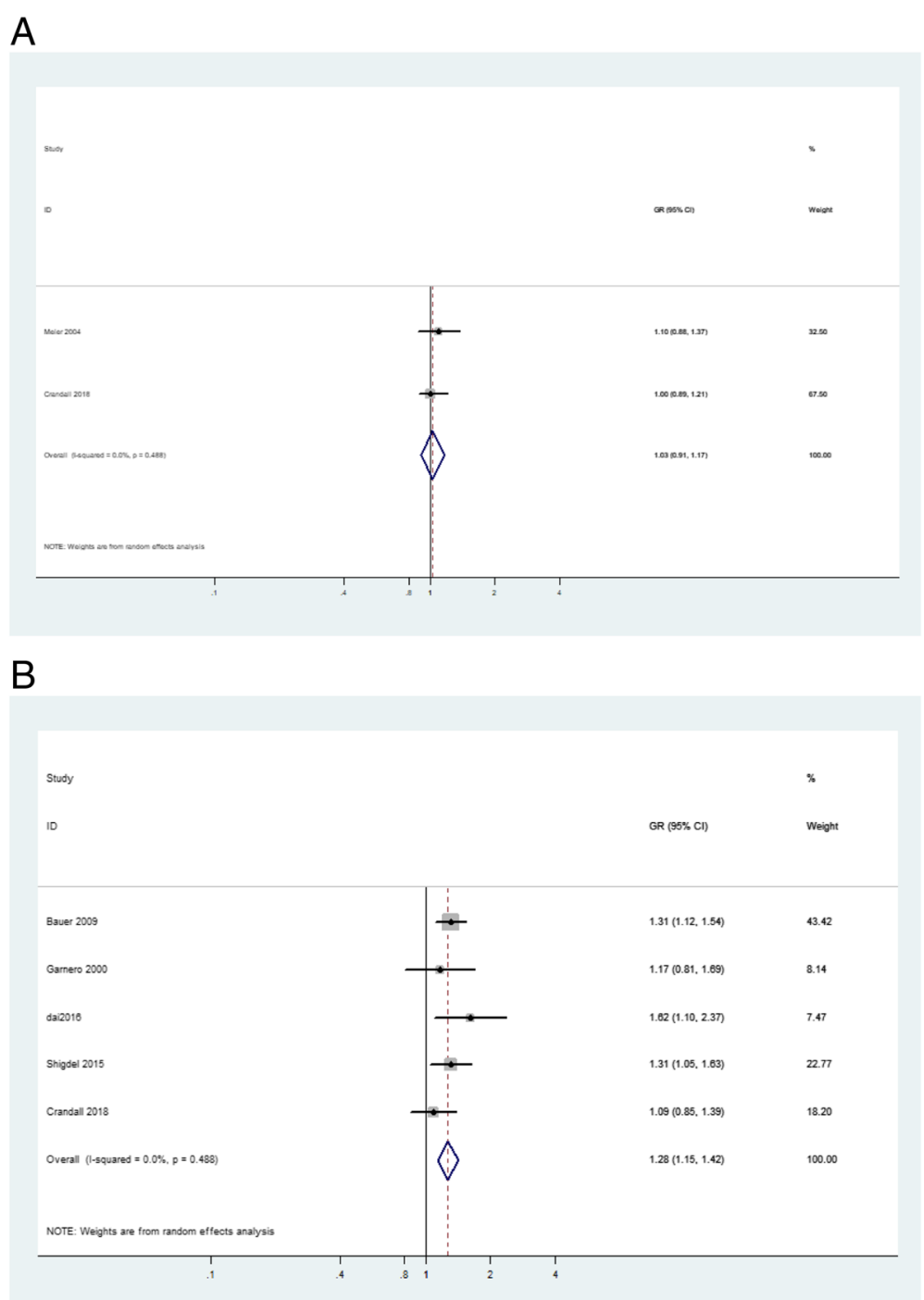

Fig. 2 Forest plot of the $\mathbf{a}$ crude and $\mathbf{b}$ adjusted associations between PINP and fracture

We obtained the full text if at least one of the reviewers judged a study to be eligible. Disagreements on inclusion were resolved by consensus. For each study, patients' characteristics including mean age, sex, duration of follow-up, state of fasting, site of fracture, trial size, and results were individually extracted.

\section{Study quality assessment}

The quality of the included citations, which was assessed by the Newcastle-Ottawa Scale, was independently scored by two authors. The scale was widely used for the evaluation of non-randomized controlled trials with respect to selection, comparability, and outcome/exposure of the enrolled studies [13]. The highest score was 9 points, and a score of $\geq 7$ points was suggestive of a high-quality study. Discrepancies between both reviewers were resolved by discussion or evaluated by the corresponding author.

\section{Outcome measures}

The primary outcome of interest was the crude and adjusted associations of BTMs (i.e., s-PINP or s-CTX) with incidence of fracture, expressed by HR for fracture per SD difference (the GR) and 95\% confidence interval (CI). It is hard to combine studies in an analysis. This is because the included studies reported the results in various ways. Some define high bone turnover as being more than 1 or 2 SDs above the mean or in the highest tertile, quartile, or quintile. To merge the results, a uniform metric was needed. The metric which we selected was the GR. Besides, if the results were reported in 
Table 3 The relationship between s-PINP and fracture risk

\begin{tabular}{|c|c|c|c|c|c|}
\hline Study & Fracture outcome & Type of unit & $\begin{array}{l}\text { Unadjusted HR } \\
\text { or OR }(95 \% \mathrm{Cl})\end{array}$ & $\begin{array}{l}\text { Adjusted } \\
\text { HR or OR }\end{array}$ & Covariates \\
\hline Garnero [14] & All & $\begin{array}{l}\text { Highest quartile } \\
\text { vs. three lower quartiles }\end{array}$ & & $1.3(0.7-2.4)$ & $\begin{array}{l}\text { Age, presence of prevalent fractures, } \\
\text { and physical activity }\end{array}$ \\
\hline \multirow[t]{2}{*}{ Meier [19] } & All & Highest vs lowest quartiles & $1.4(0.8-1.6)$ & & \\
\hline & All & Per SD & $1.1(0.9-1.4)$ & & \\
\hline \multirow[t]{4}{*}{ Bauer [21] } & Hip & $\begin{array}{l}\text { Highest quartile } \\
\text { vs. three lower quartiles }\end{array}$ & & $2.13(1.23-3.68)$ & Age and clinic \\
\hline & Nonvertebral & $\begin{array}{l}\text { Highest quartile } \\
\text { vs. three lower quartiles }\end{array}$ & & $1.57(1.21-2.05)$ & \\
\hline & Hip & $\begin{array}{l}\text { Highest quartile } \\
\text { vs. three lower quartiles }\end{array}$ & & $1.16(0.57-2.36)$ & $\begin{array}{l}\text { Age, BMl, race, diabetes, grip strength, clinic, } \\
\text { and baseline total hip BMD }\end{array}$ \\
\hline & Nonvertebral & $\begin{array}{l}\text { Highest quartile } \\
\text { vs. three lower quartiles }\end{array}$ & & $1.31(0.98-1.74)$ & \\
\hline Shigdel [10] & Hip, wrist humeral & Per SD & & $1.31(1.05-1.63)$ & $\begin{array}{l}\text { Age, height, weight, and femoral neck areal } \\
\text { bone mineral density }\end{array}$ \\
\hline \multirow[t]{2}{*}{ Dai [6] } & \multirow[t]{2}{*}{ Hip } & Highest vs lowest quartiles & & $6.63(2.02-21.81)$ & \multirow{2}{*}{$\begin{array}{l}\text { Age, sex, dialect group, date of study enrollment, } \\
\text { and date of biospecimen collection, BMl, level of } \\
\text { education, smoking status, physical activity, } \\
\text { soy isoflavones, } \beta \text {-carotene, diabetes mellitus }\end{array}$} \\
\hline & & Per SD & & $1.62(1.10-2.37)$ & \\
\hline Crandall [8] & Hip & Highest vs lowest quartiles & $1.09(0.73,1.63)$ & $1.24(0.65,2.35)$ & $\begin{array}{l}\text { Body mass index, years of education, whether living } \\
\text { with a partner, parity, smoking, fall history in past } \\
\text { year, history of previous fracture, family history of } \\
\text { hip fracture, past use of menopausal hormone } \\
\text { therapy, and vitamin D intake }\end{array}$ \\
\hline
\end{tabular}

more than one way, the GR was extracted preferentially, and if the GR was absent, we used the HR per unit of measurement. Where neither was available, the ratio of quartiles was extracted and transformed into GR by using a mathematical approximation as previously described $[11,14]$.

\section{Data synthesis and statistical analysis}

All results summarized using the Stata software package (version 12.0). We calculated GR with 95\% CI. Data were pooled using a random effects model to give a more conservative estimate of the effect. Heterogeneity between studies was assessed using both the $I^{2}$ statistic with a cut off of $\geq 50 \%$, and the $X^{2}$ test with a $P$ value $<0.10$ used to define a significant degree of heterogeneity [15]. The subgroup analysis was conducted based on gender (male or female), age (more than 65), and site of fracture (hip fracture). In order to assess the influence of individual studies on the pooled result, we conducted a sensitivity analysis by excluding each study one by one and recalculating the combined estimates on the remaining studies.

The funnel plot along with Begg's test was performed to plot the log GR against its standard error for evaluation of publication bias, while the extent of asymmetry was assessed by Egger's unweighted regression asymmetry test [16]. We used two-tailed $P$ values and $P<$ 0.05 was regarded as statistical significance except that for determining heterogeneity $(P<0.1)$

\section{Results}

Study characteristics and quality assessment

A flowchart of study search and selection was presented in Fig. 1. In brief, we identified 1041 references in our literature search and out of 34 potentially eligible studies, 10 articles describing 9 trials met our inclusion criteria and were included in the meta-analysis $[6-8,10$, 14, 17-21]. Gerdhem et al. [17] and Ivaska et al. [18] studied the same cohort but had different follow-up time. The study with the shorter follow-up was selected for inclusion in the meta-analysis because the study of Ivaska et al. [18] reported a time interaction. Finally, nine articles were chosen in our study $[6-8,10,14,17$, 19-21].

Table 1 lists the characteristics of eligible and included studies. A total of 11,572 participants were included in this meta-analysis. The average follow-up time ranged from 2.0 to 7.13 years. In terms of the targeted population, the age of the observed population ranged from 45 to 89 years. Five studies enrolled elderly people only (> 65 years of age) [7,17, 19-21], and other four studies enrolled both elders and middle-aged persons $[6,8,10$, 

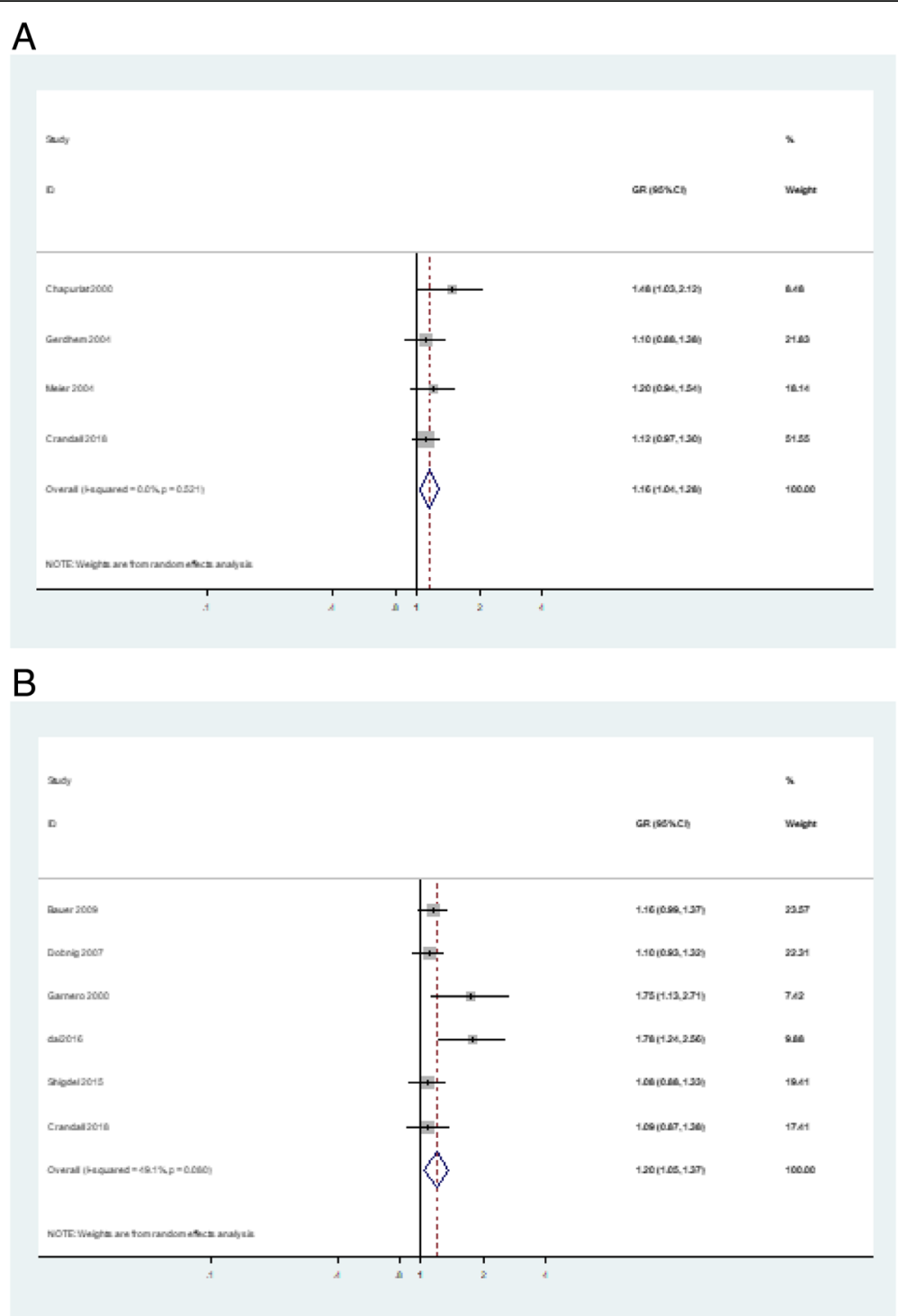

Fig. 3 Forest plot of the $\mathbf{a}$ crude and $\mathbf{b}$ adjusted associations between CTX and fracture

14]. Six studies presented results for women [7, 8, 10, $14,17,20]$, two studies presented results for men [19, $21]$, and one article presented results for men and women combined [6]. Regarding the fasting state of included participants, five studies tested participants in fasting state $[6,8,10,14,21]$, three studies were in non-fasting state $[17,19,20]$, and one study was not clear about the fasting state [7]. In terms of fracture site, six studies reported hip fracture [6-8, 17, 20, 21], other studies presented various sites of fracture.

The study quality scores are summarized in Table 2. The range of quality scores was from 4 to 8 ; the median score was 7 . High-quality studies (i.e., those having $\geq 7$ awarded stars) included six studies [6-8, 10, 17, 19].

\section{Overall analysis}

The crude GR and adjusted GR between s-PINP and fracture was extracted from two studies $[8,19]$ and five studies $[6,8,10,14,21]$, respectively (Table 2). As shown in Fig. 2, s-PINP was not associated with fracture without adjusting for covariates (crude GR, 1.03; 95\% CI, 0.91-1.17). After adjusting for potential confounders such as age, body mass index, mobility score, past fractures, and hip BMD, s-PINP demonstrated a significant positive association with fracture (adjusted GR, 1.28; 95\% CI, 1.15-1.42), which indicated that a 1 SD increment in s-PINP was associated with an increased risk of fracture of $28 \%$. The subgroup analysis showed that s-PINP tended to be associated with fracture in women (adjusted GR, 1.25; 95\% CI, 1.08-1.45). It turned out 

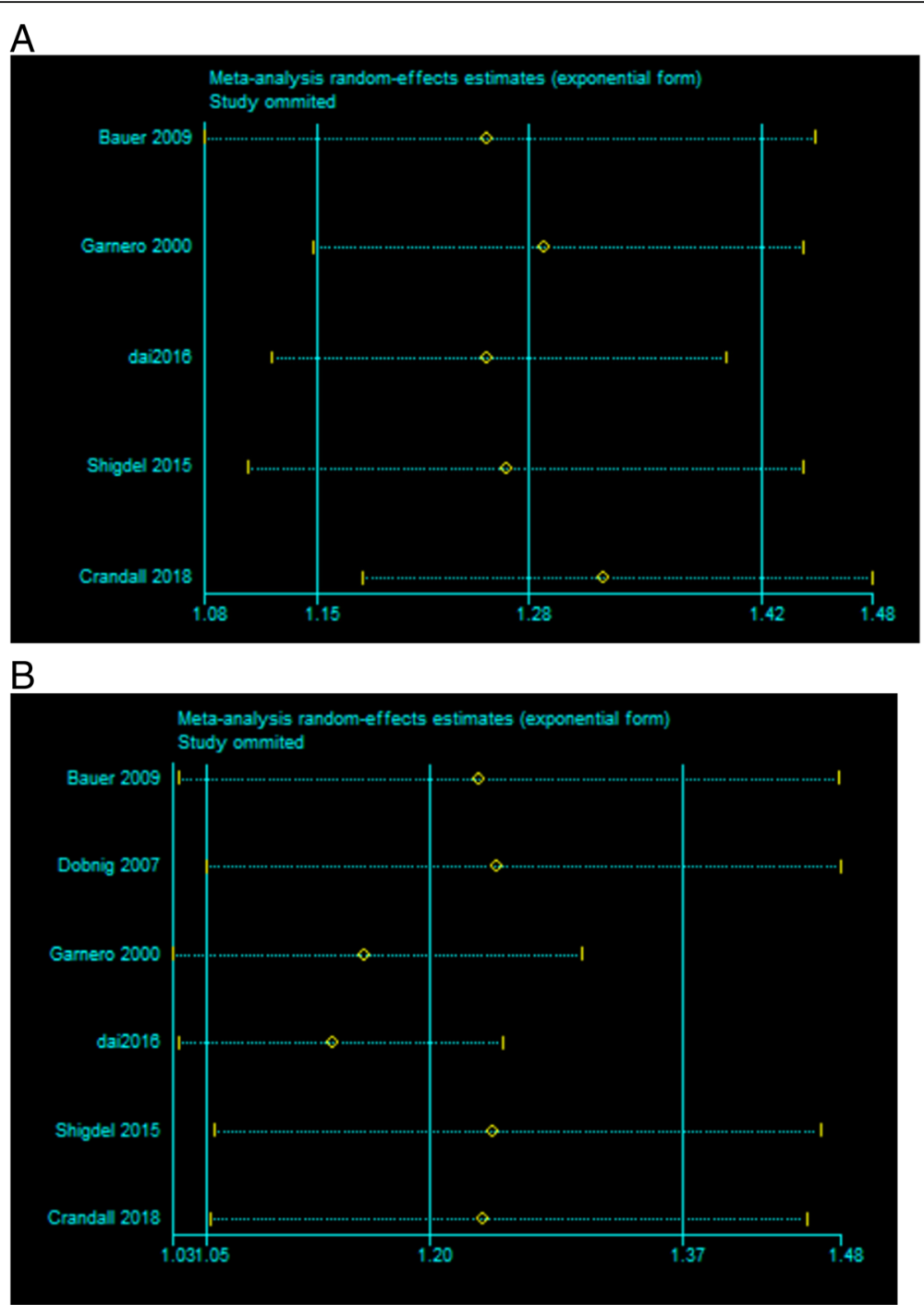

Fig. 4 Sensitivity analysis of adjusted GR: a PINP, b CTX

that s-PINP was not associated with hip fracture (adjusted GR, 1.29; 95\% CI, 0.88-1.90). The results of the Egger's and Begg's test indicated the absence of publication bias in adjusted GR $(P$ values $=0.923)$ (Additional file 1: Figure S1).

The crude GR and adjusted GR between s-CTX and fracture was extracted from four studies [7, 8, 17, 19] and six studies $[6,8,10,14,20,21]$, separately (Table 3 ). Both crude GR $(1.16,95 \% \mathrm{CI}, 1.04-1.20)$ and adjusted GR (1.20, 95\%CI, 1.05-1.37) shown a significant positive result. And subgroup analysis showed a mildly significant association between S-PINP and fracture in the group of elderly, female, and hip fracture patients (Fig. 3). The results of the Egger's and Begg's test indicated the existence of publication bias in adjusted GR but not in crude GR ( $P$ values $=0.034$ for crude $G R$ and 0.178 for adjusted GR) (Additional file 1: Figure S1).

\section{Sensitivity analysis}

In sensitivity analyses, we recalculated the combined results by excluding one study per iteration. The adjusted GRs between s-PINP and fracture ranged from a low of 1.25 (95\% CI: 1.08, 1.45) to a high of 1.32 (95\% CI: $1.18,1.48)$ via omission of the study by Bauer et al. [21] and via omission of the study by Crandall et al. [8] respectively. And the adjusted GRs between s-CTX and fracture ranged from a low of 1.14 (95\% CI: 1.03, 1.25) to a high of 1.25 (95\% CI: $1.05,1.48)$ via omission of the study by Dai et al. [6] and via omission of the study by Dobnig et al. [20] respectively. Both results were similar without great fluctuate (Fig. 4).

\section{Discussion}

The present study aimed to integrate the most updated evidence to evaluate the association between 
BTMs (i.e., s-PINP or s-CTX) and the incidence of fracture. The overall results indicated that s-PINP and s-CTX were positively associated with fracture after adjusting for relevant covariates when we chose the expression of risk as the gradient of fracture risk per SD difference in BTM. This combined estimate was robust across sensitivity analyses. The stratified analysis further showed that there was a statistically significant but modest association between CTX and fracture in the group of elderly, female, and hip fracture patients. Besides, there was a significant association between PINP and fracture in women.

The ability to predict fractures is limited and needs further development. BTMs reflect bone formation and resorption and therefore inform the status of bone remodeling. Thus, the measurement of BTMs may serve either as an independent diagnostic and prognostic index or as a complementary indicator to BMD for fractures. It was suggested that PINP and CTX-I were the best risk predictors for fractures [2, 6]. A number of studies have attempted to make certain the impact of PINP and CTX-I on incident fracture in the middle-aged and elderly people, but failed to reach an agreement [2]. To our best of knowledge, data should also be adjusted for BMD and clinical risk factors so that the BTM are evaluated for their value in fracture risk prediction algorithms. Collectively, based on the conflicting results across studies and the significance of both clinical conditions, a meta-analysis was conducted to investigate the independent role of BTM in fracture risk prediction.

In line with the recommended analytes by the IOF and IFCC, our data confirmed that PINP and CTX-I could be the risk predictors for fractures because BTMs play a central role directly and indirectly in the mechanical resistance of the skeleton [22]. Besides, our main results were consistent with a previous meta-analysis showing there was a moderate but significant association between s-PINP, s-CTX, and risk of fracture, which was not adjusted for BMD and/or other relevant covariates [11]. As for the crude GR between s-PINP and fracture, there were just two articles included in our study, so it may need more evidence to illustrate the relationship.

It is not surprising that BTMs are significantly associated with fracture incidence in women more than

Table 4 The relationship between s-CTX and fracture risk

\begin{tabular}{|c|c|c|c|c|c|}
\hline Study & $\begin{array}{l}\text { Fracture } \\
\text { outcome }\end{array}$ & Type of unit & $\begin{array}{l}\text { Unadjusted } \\
\text { HR or OR }(95 \% \mathrm{Cl})\end{array}$ & $\begin{array}{l}\text { Adjusted } \\
\text { HR or OR }\end{array}$ & Covariates \\
\hline Chapurlat [7] & Hip & Highest quartile vs control & $1.9(1.05-3.4)$ & & \\
\hline Garnero [14] & All & Highest vs lowest quartiles & & $2.1(1.2-3.8)$ & $\begin{array}{l}\text { Age, presence of prevalent fractures, } \\
\text { and physical activity }\end{array}$ \\
\hline \multirow[t]{3}{*}{ Gerdhem [17] } & All & \multirow{3}{*}{$\begin{array}{l}\text { Highest quartile vs. } \\
\text { three lower quartiles }\end{array}$} & $1.18(0.81-1.70)$ & & \\
\hline & Hip & & $1.01(0.48-2.11)$ & & \\
\hline & Vertebral & & $1.94(1.05-3.58)$ & $1.58(0.83-2.98)$ & Lumbar spine BMD \\
\hline \multirow[t]{2}{*}{ Meier [19] } & All & Highest vs lowest quartiles & $1.6(0.8-3.3)$ & & \\
\hline & All & Per SD & $1.2(0.98-1.6)$ & & \\
\hline \multirow[t]{2}{*}{ Dobnig [20] } & Hip & \multirow[t]{2}{*}{ Per increment of $1 \mathrm{ng} / \mathrm{mL}$} & & $1.27(0.45-3.6)$ & \multirow{2}{*}{$\begin{array}{l}\text { Age, BMI, mobility score, past fractures, } \\
\text { creatinine clearance rate, calcaneal stiffness }\end{array}$} \\
\hline & Nonvertebral & & & $1.41(0.77-2.6)$ & \\
\hline \multirow[t]{4}{*}{ Bauer [21] } & Hip & \multirow{4}{*}{$\begin{array}{l}\text { Highest quartile vs } \\
\text { three lower quartiles }\end{array}$} & & $1.76(1.04-2.98)$ & \multirow[t]{4}{*}{ Age and clinic } \\
\hline & Nonvertebral & & & $1.29(0.99-1.69)$ & \\
\hline & Hip & & & $1.04(0.55-1.97)$ & \\
\hline & Nonvertebral & & & $1.07(0.80-1.42)$ & \\
\hline \multirow[t]{2}{*}{ Ivaska [18] } & All & \multirow[t]{2}{*}{ Per SD } & $1.13(1.01,1.27)$ & & \\
\hline & Vertebral & & $1.32(1.05,1.67)$ & & \\
\hline Shigdel [10] & Hip, wrist & Per SD & & $1.08(0.88-1.33)$ & $\begin{array}{l}\text { Age, height, weight, and femoral neck areal } \\
\text { bone mineral density }\end{array}$ \\
\hline \multirow[t]{2}{*}{ Dai [6] } & \multirow[t]{2}{*}{ Hip } & Highest vs lowest quartiles & & $4.92(1.67-14.51)$ & \multirow{2}{*}{$\begin{array}{l}\text { Age, sex, dialect group, date of study enrollment, } \\
\text { BMl, level of education, smoking status, } \\
\text { physical activity, diabetes mellitus }\end{array}$} \\
\hline & & Per SD & & $1.78(1.24-2.56)$ & \\
\hline Crandall [8] & Hip & Highest vs lowest quartiles & $1.33(0.91,1.96)$ & $1.25(0.68,2.30)$ & $\begin{array}{l}\text { Body mass index, years of education, whether living } \\
\text { with a partner, parity, smoking, fall history in past } \\
\text { year, history of previous fracture, family history of } \\
\text { hip fracture, past use of menopausal hormone } \\
\text { therapy, and vitamin D intake }\end{array}$ \\
\hline
\end{tabular}


45 years old. At menopause, there is an acceleration in the rate of bone loss, and this is naturally related to the increase in bone turnover. And higher levels of BTMs were associated with higher cortical porosity and thinner cortices, which may lead to the incidence of fracture [10]. As we know, the elderly have always been subject to fractures. BTMs increased during aging in both men and women and have been suggested to be independent risk factors for fractures $[23,24]$. Therefore, there might be age interaction between the BTMs and fracture risk.

Other forms of utilization about BTMs should also be taken into consideration in the future study. Joint effect of serum PINP and CTX-I on the risk of hip fracture seems to be stronger [6]. Lower serum PINP/CTX ratio demonstrated an inverse dose-effect relationship with the prevalence of nonvertebral fractures [9] (Table 4).

There are several limitations in this meta-analysis which need to be considered. Firstly, in the absence of access to primary data, we standardize the metric of predictive power (the GR) to maximize the use that can be made of publications that used differing indices of risk. Secondly, although most studies report a positive association between BTM and fracture risk, each study has several fracture endpoints, so these could be false positives. It would be better to define the reference range of BTM along with single fracture type. Thirdly, the included studies have different settings for adjustment. Also, we did not have information about recent fracture in the cohorts, and the association between markers and fracture risk may be confounded by a history of prior fracture.

\section{Conclusions}

In conclusion, BTMs hold promise as an independent predictor for fracture. However, before they can be used for this purpose in clinical practice, we need further carefully conducted prospective studies which are analyzing BTMs in a standard manner (such as relative risk per SD increase) for a single fracture type.

\section{Additional file}

Additional file 1: Figure S1. BEGG's funnel plot of adjusted GR:(A)PINP; (B)CTX. (DOCX $898 \mathrm{~kb})$

\section{Abbreviations}

BMD: Bone mineral density; BTMs: Bone turnover biomarkers; $\mathrm{Cl}$ : Confidence interval; CRFs: Clinical risk factors; CTX: C-terminal telopeptide of type I collagen; GR: Gradient of risk; IFCC: International Federation of Clinical Chemistry; IOF: International Osteoporosis Foundation; PINP: Procollagen type I aminoterminal propeptide; SD: Standard deviation

\section{Acknowledgments}

None

\section{Funding}

Technology fund of Tianjin Health and Family Planning Commision (2015KZ065).

\section{Availability of data and materials}

All data generated or analysed during this study are included in this published article [and its supplementary information files.

\section{Author's contributions}

AT and XM designed the research. JM and AT conducted the research. KF and ZL performed the statistical analysis. LC and HJ wrote the paper. All authors read and approved the final manuscript.

Ethics approval and consent to participate

Not applicable.

\section{Consent for publication}

Written informed consent was obtained from all patients for data publication, including images.

\section{Competing interests}

The authors declare that they have no competing interests.

\section{Publisher's Note}

Springer Nature remains neutral with regard to jurisdictional claims in published maps and institutional affiliations.

\section{Author details}

${ }^{1}$ Tianjin Hospital, Tianjin University, Tianjin 300211, China. ${ }^{2}$ Department of Clinical Laboratory, Tianjin Hospital, Tianjin 300211, China. ${ }^{3}$ Department of Otolaryngology, The Second Hospital of Tianjin Medical University, Tianjin 300211, China. ${ }^{4}$ Department of Orthopedics Institute, Tianjin Hospital, Tianjin 300211, China.

Received: 29 October 2018 Accepted: 13 February 2019

Published online: 28 February 2019

\section{References}

1. Bliuc D, Nguyen ND, Milch VE, Nguyen TV, Eisman JA, Center JR. Mortality risk associated with low-trauma osteoporotic fracture and subsequent fracture in men and women. Jama. 2009;301:513-21.

2. Vilaca T, Gossiel F, Eastell R. Bone turnover markers: use in fracture prediction. Journal of Clinical Densitometry the Official Journal of the International Society for Clinical Densitometry. 2017;5:346-52.

3. Nguyen ND, Eisman JA, Center JR, Nguyen TV. Risk factors for fracture in nonosteoporotic men and women. J Clin Endocrinol Metab. 2007;92:955-62.

4. Kanis JA, Harvey NC, Johansson H, Odén A, Leslie WD, Mccloskey EV. FRAX and fracture prediction without bone mineral density. Climacteric. 2015;18:2-9.

5. Bauer D, Lane N, Leary E, Libanati C, Miller P, Myers G, Silverman S, Vesper HW, Lee D, Payette M. National Bone Health Alliance Bone Turnover Marker Project: current practices and the need for US harmonization, standardization, and common reference ranges. Osteoporos Int. 2012;23: 2425-33.

6. Dai Z, Wang R, Ang LW, Yuan JM, Koh WP. Bone turnover biomarkers and risk of osteoporotic hip fracture in an Asian population. Bone. 2016:83:171-7.

7. Chapurlat RD, Garnero P, Bréart G, Meunier PJ, Delmas PD. Serum type collagen breakdown product (serum CTX) predicts hip fracture risk in elderly women: the EPIDOS study. Bone. 2000;27:283-6.

8. Crandall CJ, Vasan S, Lacroix A, Leboff MS, Cauley JA, Robbins JA, Jackson $\mathrm{RD}$, Bauer DC. Bone turnover markers are not associated with hip fracture risk: a case-control study in the Women's Health Initiative. Journal of Bone \& Mineral Research the Official Journal of the American Society for Bone \& Mineral Research. 2018.

9. Fisher A, Srikusalanukul W, Fisher L, Smith PN. Lower serum P1NP/BCTX ratio and hypoalbuminemia are independently associated with osteoporotic nonvertebral fractures in older adults. Clin Interv Aging. 2017;12:1131.

10. Shigdel R, Osima M, Ahmed LA, Joakimsen RM, Eriksen EF, Zebaze R, Bjørnerem Å. Bone turnover markers are associated with higher cortical porosity, thinner cortices, and larger size of the proximal femur and nonvertebral fractures. Bone. 2015;81:1-6. 
11. Johansson H, Odén A, Kanis JA, Mccloskey EV, Morris HA, Cooper C, Vasikaran $\mathrm{S}$. A meta-analysis of reference markers of bone turnover for prediction of fracture. Calcif Tissue Int. 2014;94:560-7.

12. Marshall J. The use of clinical risk factors enhances the performance of BMD in the prediction of osteoporotic fractures in men and women. Osteoporos Int Osteoporosis international : a journal established as result of cooperation between the European Foundation for Osteoporosis and the National Osteoporosis Foundation of the USA. 2007;18:1033.

13. Stang A. Critical evaluation of the Newcastle-Ottawa scale for the assessment of the quality of nonrandomized studies in meta-analyses. Eur J Epidemiol. 2010;25:603-5.

14. Garnero P. Markers of bone turnover for the prediction of fracture risk. Osteoporos Int. 2000;11:S55-65.

15. Higgins JP, Thompson SG, Deeks JJ, Altman DG. Measuring inconsistency in meta-analyses. BMJ (Clinical research ed). 2003;327:557-60.

16. Langhorne P. Bias in meta-analysis detected by a simple, graphical test. Prospectively identified trials could be used for comparison with metaanalyses. BMJ (Clinical research ed). 1998;316:471.

17. Gerdhem P, Ivaska KK, Alatalo SL, Halleen JM, Hellman J, Isaksson A, Pettersson K, Vaananen HK, Akesson K, Obrant KJ. Biochemical markers of bone metabolism and prediction of fracture in elderly women. Journal of bone and mineral research : the official journal of the American Society for Bone and Mineral Research. 2004;19:386-93.

18. Ivaska KK, Gerdhem P, Väänänen HK, Akesson K, Obrant KJ. Bone turnover markers and prediction of fracture: a prospective follow-up study of 1040 elderly women for a mean of 9 years. Journal of Bone \& Mineral Research. 2010;25:393-403.

19. Meier C, Nguyen TV, Center JR, Seibel MJ, Eisman JA (2004) Bone resorption rate is an independent predictor of osteoporotic fractures in elderly men. The dubbo study. Calcified Tissue International 74:S65-S65.

20. Dobnig H, Piswangersölkner JC, Obermayerpietsch B, Tiran A, Strele A, Maier E, Maritschnegg P, Riedmüller G, Brueck C, Fahrleitnerpammer A. Hip and nonvertebral fracture prediction in nursing home patients: role of bone ultrasound and bone marker measurements. J Clin Endocrinol Metab. 2007;92:1678-86.

21. Bauer DC, Garnero P, Harrison SL, Cauley JA, Eastell R, Ensrud KE, Orwoll E. Biochemical markers of bone turnover, hip bone loss, and fracture in older men: the MrOS study. Journal of bone and mineral research : the official journal of the American Society for Bone and Mineral Research. 2009;24: 2032-8.

22. Johnell O, Odén A, Laet CD, Garnero P, Delmas PD, Kanis JA. Biochemical indices of bone turnover and the assessment of fracture probability. Osteoporos Int. 2002;13:523-6.

23. Alvarez-Rios Al, Guerrero JM, Garcia-Garcia FJ, Rodriguez-Manas L, MedranoCampillo P, de la Torre Lanza MA, Alvarez-Sanchez N, Carrillo-Vico A. Associations between frailty and serum $\mathrm{N}$-terminal propeptide of type I procollagen and 25-hydroxyvitamin D in older Spanish women: the Toledo Study for Healthy Aging. Exp Gerontol. 2015;69:79-84.

24. Eastell R, Hannon RA. Biomarkers of bone health and osteoporosis risk. Proc Nutr Soc. 2008;67:157.

Ready to submit your research? Choose BMC and benefit from:

- fast, convenient online submission

- thorough peer review by experienced researchers in your field

- rapid publication on acceptance

- support for research data, including large and complex data types

- gold Open Access which fosters wider collaboration and increased citations

- maximum visibility for your research: over $100 \mathrm{M}$ website views per year

At BMC, research is always in progress.

Learn more biomedcentral.com/submissions 